\title{
Previous consultation and self reported health status as predictors of future demand for primary care
}

\author{
K Jordan, B N Ong, P Croft
}

J Epidemiol Community Health 2003;57:109-113

\begin{abstract}
Study objective: There has been little prospective investigation of what predicts general practice consultation. The objective of this study was to investigate the extent to which previous primary care consultation and self reported health status are predictors of future primary care consultation.

Design: Population based cohort study in two phases. Firstly, a baseline survey (1995/96) to identify the cohort and to obtain self reported health status using the UK census limiting long term illness (LLI) question and the Short Form-36 (SF-36) health profile. Secondly, analysis of general practice medical records for two years (1994/1995) before the survey and for two years (1997/1998) after the survey. Analysis was performed on: (a) all contacts coded by the GP, (b) the subgroup of contacts given a diagnostic morbidity code by the GP.

Setting: One general practice in North Staffordshire, UK.

Participants: 738 survey respondents who had consented to viewing of medical records including all those who reported LLI together with an age-gender matched control group of those who reported no LLI.

Main results: High frequency consulters in 1994/95 were more likely than non-consulters or average consulters in that year to be high consulters in 1997/98 lodds ratio 5.6, 95\% confidence interval 3.82 to 8.25 , for all contacts; 4.4 for diagnostic coded consultations). Self reported role disability and physical limitation from the SF-36 at baseline increased the probability of being a future high consulter but the effects were weaker than for previous consultation. Previous consultation within a diagnostic group was the main predictor for future consultation within that group with weaker but significant prediction by self reported health status.

Conclusions: Reliable morbidity coding in general practice provides the best available basis for predicting future demand in primary care. Self reported health status survey instruments add to this information but on their own are weaker predictors of future consultation.
\end{abstract}

See end of article for authors' affiliations

.......................

Correspondence to: Dr K Jordan, Primary Care Sciences Research Centre, Hornbeam Building, Keele University, Keele, Staffordshire ST5 5BG, UK; k.p.jordan@keele.ac.uk

Accepted for publication 15 July 2002 n the United Kingdom, general practices have now been formed into groups with budget and commissioning responsibility and, hence, need to plan for future demands on health care. The primary care consultation is an important measure of such demand. Simple indicators of future consultation rates would thus help planning in primary care.

Such indicators might include routine general practice data such as current consultation patterns or demographic characteristics. Alternatively, they might be obtained from surveys of the population such as national census data or local studies. Studies have explored social and economic correlates of general practice consultations, ${ }^{1-3}$ but there has been little prospective investigation of what predicts consultation patterns.

We carried out a cohort study of a population registered with one general practice to investigate whether consultation patterns and survey derived health status are linked with future consultation rates.

\section{METHODS}

The design was a cohort study, consisting of a baseline survey to identify the cohort and to measure self reported health status, a baseline record review to measure consultation patterns prior to the baseline survey, and a prospective record review to determine the primary outcome (future consultation).

\section{Baseline survey}

In 1995/96 we surveyed health status in an adult population. The study was set in a suburban general practice in North Staffordshire, UK. The sampling frame was the registered practice population aged 18 and above. In the UK, most of the population is registered with a general practice irrespective of use of the service and so the register of any practice provides an effective sampling frame of the local population. The practice area had a high prevalence of limiting long term illness (LLI) according to the 1991 UK census but also represented a broad socioeconomic range. The practice is a member of the North Staffordshire General Practice Research Network, a group of practices committed to recording all consultations on a computerised system and to six monthly audits of their coding patterns. The practice currently has six GPs and 8000 registered patients aged 18 and over.

The baseline survey was in two phases. Phase I used a question identical to the 1991 UK census inquiry about LLI to survey a random sample of 4044 registered patients aged 18 and over. In Phase II, a health profile tool, the Short Form-36 (SF36), was sent to all Phase I responders who had reported LLI and to an age-gender frequency matched control group sampled from Phase I responders who reported no LLI. A full account and analysis of the baseline survey has appeared elsewhere. ${ }^{4}$

\section{Follow up study}

Of the 886 subjects ( 455 LLI, 431 non-LLI) who responded to the SF-36 survey and consented to their medical records being reviewed (47\% overall response), 113 had departed the practice and 35 had died before the end of 1998. These were removed from the analysis leaving 738 subjects ( 377 non-LLI, 361 LLI) as the study population for this cohort analysis. There was no difference in response rates between the LLI and nonLLI groups. There was no difference between responders and non-responders on gender or area of residence. The only 
difference was that responders in the non-LLI group were slightly older than non-responders.

\section{Self report measures}

The LLI question asked: "Do you have any long-term illness, health problem or handicap which limits your normal daily activities or the work you can do? Include problems which are due to old age". The SF- $36^{5}$ consists of 36 questions on eight different dimensions of health. We categorised responders according to four dichotomous indicators ${ }^{6}$ : (1) The physical limitations indicator signifies the subject has reported "Yes, limited a lot" on at least one of the Physical Functioning questions. (2) The emotional limitations indicator signifies a subject has a score of 52 or less on the Mental Health scale. (3) The role disability indicator signifies a subject has reported a physical or emotional role limitation. For example, cutting down amount of time on work or other activities because of physical or emotional health. (4) The unfavourable personal evaluation indicator signifies a subject who has rated their health in general to be "poor" or "fair".

\section{Demographic measures}

Apart from age and gender, the Townsend index ${ }^{7}$ was incorporated as a proxy measure of social deprivation. This index is a composite score of the unemployment, overcrowding, non-car ownership, and non-home ownership variables from the UK census, calculated at the smallest geographical level of the census (the enumeration district). Enumeration districts were linked to the subjects' postcodes and each district score calculated relative to the score for the total area covered by the practice. This score was then allocated to the individual as an "ecological measure".

\section{Measures of consultation}

The Read code system is the standard for recording clinical information in the UK NHS. It allows primary health care workers to code consultations by diagnosis, presenting symptom or procedure undertaken. ${ }^{8}$ A "consultation" was defined in this study as any contact (surgery visit, telephone, home visit) recorded and given a Read code by a general practitioner. These will include process of care contacts (influenza vaccination, for example), contacts coded with non-specific symptom codes, and illness labels recorded by the GP under one of the diagnostic Chapters (Chapters A-R) in the Read Code system. Audits of the practice in 1998 showed that $99 \%$ of all consultations to a GP at the practice were given a Read Code and over $90 \%$ of patients taking selected drugs had the relevant morbidity code in their record.
An additional subgroup analysis was restricted to consultations coded into one of the diagnostic Chapters, which represent the broad presenting condition (for example, musculoskeletal, mental health). In 1997/98, 60\% of all GP contacts in the study practice were recorded in the diagnostic Chapters.

\section{Analysis}

The first outcome was frequency of consultation in 1997/98 (non, average, or high) defined from the quartile distribution. For the "all contacts" analysis, high consultation was defined as nine or more over the two year period, based on the upper quartile value for the 1997/98 period; for the diagnostic Chapter subgroup analysis, five or more consultations was the upper quartile value. Average consulters were consulters below the upper quartile. Non-consulters had no contacts during the two year period.

Two types of analysis were performed. Firstly, baseline characteristics in high consulters 1997/98 were compared with non-consulters and average consulters using binary logistic regression. Self reported LLI, the four SF-36 indicators and whether the subject was a high consulter or not in 1994/95 were predictor variables. Age, gender, and Townsend deprivation score were included as potential confounders. Initially, previous consultation (1994/95) and the LLI indicator were included in the model with the potential confounders to explore how a simple, single health question might predict consultation behaviour. A second model was derived using a stepwise forward method of model selection, using all the variables, to determine any improvement in prediction from using the SF-36. A significance level of 0.05 was used to determine selection.

In the second analysis, ordered logit regression was used, with trichotomous consultation status in 1997/98 (non, average, or high) as the outcome. Consultation in 1994/95 was also trichotomised with two dummy variables (high and average consultation, with non-consultation as the reference category). The probability of being a high consulter in 1997/98 was then ascertained based on different combinations of the predictor variables.

These analyses were performed separately for all contacts and for the subgroup of consultations coded to a diagnostic Chapter. Finally, the first (stepwise) analysis procedure was repeated separately for each diagnostic Read Code Chapter to assess predictors of consultation in 1997/98 from baseline measures for each Chapter. Only Chapters with 50 or more consulters in 1997/98 were assessed.

Analyses were performed using SPSS for Windows $10.0^{10}$ and Stata 6.0. ${ }^{11}$

Table 1 Baseline characteristics by frequency of consultation in 1997/98

\begin{tabular}{|c|c|c|c|c|c|}
\hline & \multirow[b]{3}{*}{ Total } & \multicolumn{4}{|c|}{ Frequency of consultation $97 / 98$} \\
\hline & & \multicolumn{2}{|l|}{ All contacts } & \multicolumn{2}{|c|}{ Diagnostic (A-R) Chapters only } \\
\hline & & Non/Average & High & Non/Average & High \\
\hline Number* & 738 & 544 & 194 & 530 & 208 \\
\hline \multicolumn{6}{|l|}{ Age } \\
\hline mean (SD) & $58.3(14.28)$ & $57.9(14.22)$ & $61.4(14.18)$ & $57.9(14.16)$ & $61.1(14.37)$ \\
\hline median & 60 & 59 & 61 & 59 & 62 \\
\hline Female & $404(55 \%)$ & $274(50 \%)$ & $130(67 \%)$ & $274(52 \%)$ & $130(63 \%)$ \\
\hline \multicolumn{6}{|l|}{ High consulter 94/95 } \\
\hline All contacts & $225(30 \%)$ & $105(19 \%)$ & $120(62 \%)$ & - & - \\
\hline A-R only & $249(34 \%)$ & - & - & $121(23 \%)$ & $128(62 \%)$ \\
\hline Report LLI & $361(49 \%)$ & $232(43 \%)$ & $129(66 \%)$ & $225(42 \%)$ & $136(65 \%)$ \\
\hline \multicolumn{6}{|l|}{ SF-36 indicators } \\
\hline Physical Limitations & $353(48 \%)$ & $226(42 \%)$ & $127(65 \%)$ & $215(41 \%)$ & $138(66 \%)$ \\
\hline Emotional Limitations & $106(15 \%)$ & $67(13 \%)$ & $39(20 \%)$ & $63(12 \%)$ & $43(21 \%)$ \\
\hline Role Disability & $397(54 \%)$ & $258(49 \%)$ & $139(73 \%)$ & $248(48 \%)$ & $149(74 \%)$ \\
\hline Unfavourable Personal Evaluation & $236(32 \%)$ & $143(26 \%)$ & $93(48 \%)$ & $137(26 \%)$ & $99(48 \%)$ \\
\hline
\end{tabular}

*Number will be lower for the SF-36 indicators because of missing data on the questionnaire; percentages relate to the percentage of the total number for that column. 
Table 2 Predictors for high consultation in 1997/98*

\begin{tabular}{|c|c|c|c|c|c|c|}
\hline \multirow[b]{2}{*}{ High consulter $97 / 98$} & \multicolumn{6}{|l|}{ OR $(95 \% \mathrm{Cl})$} \\
\hline & $\begin{array}{l}\text { High consulter } \\
94 / 95 \text { ( } v \text { non or } \\
\text { average consulter) }\end{array}$ & $\begin{array}{l}\text { LLI at baseline } \\
\text { ( } v \text { no LLI) }\end{array}$ & $\begin{array}{l}\text { Physical Limitation } \\
\text { ( } v \text { no limitation) }\end{array}$ & $\begin{array}{l}\text { Emotional } \\
\text { Limitation } \\
\text { ( } v \text { no limitation) }\end{array}$ & $\begin{array}{l}\text { Role Disability } \\
\text { ( } v \text { no disability) }\end{array}$ & $\begin{array}{l}\text { Unfavourable } \\
\text { Health Evaluation } \\
\text { ( } v \text { favourable) }\end{array}$ \\
\hline All contacts $\dagger$ & $\begin{array}{l}5.61 \\
(3.82 \text { to } 8.25)\end{array}$ & $\begin{array}{l}1.58 \\
(1.06 \text { to } 2.37)\end{array}$ & & & & \\
\hline Diagnostic Chapters $†$ & $\begin{array}{l}4.44 \\
(3.09 \text { to } 6.38)\end{array}$ & $\begin{array}{l}1.82 \\
(1.25 \text { to } 2.66)\end{array}$ & & & & \\
\hline All contacts $\ddagger$ & $\begin{array}{l}6.18 \\
(4.20 \text { to } 9.10)\end{array}$ & - & - & - & $\begin{array}{l}1.89 \\
(1.26 \text { to } 2.84)\end{array}$ & - \\
\hline Diagnostic Chapters $\ddagger$ & $\begin{array}{l}4.53 \\
(3.08 \text { to } 6.66)\end{array}$ & - & $\begin{array}{l}1.59 \\
(1.02 \text { to } 2.49)\end{array}$ & - & $\begin{array}{l}1.72 \\
(1.12 \text { to } 2.64)\end{array}$ & - \\
\hline
\end{tabular}

*Adjusted for age, gender, Townsend deprivation score, and other variables in model. †Only high consultation 1994/95 and LLI at baseline indicator variables entered. ‡stepwise selection procedure of all explanatory variables.

\begin{tabular}{|c|c|c|c|}
\hline \multicolumn{4}{|c|}{$\begin{array}{l}\text { Table } 3 \text { Estimated probability of being a high consulter in } 1997 / 98 \text { for } 50 \text { year } \\
\text { old woman residing in area with Townsend score } 0\end{array}$} \\
\hline \multicolumn{2}{|c|}{ Predictors } & \multirow{2}{*}{$\begin{array}{l}\text { All contacts } \\
49\end{array}$} & \multirow{2}{*}{$\begin{array}{l}\text { Diagnostic } \\
\text { Chapters } \\
47\end{array}$} \\
\hline 1 & High consulter 94/95 & & \\
\hline & Average consulter $94 / 95$ & 19 & 22 \\
\hline & Non-consulter $94 / 95$ & 11 & 13 \\
\hline \multirow[t]{2}{*}{2} & High consulter 94/95 + LLI & 52 & 52 \\
\hline & High consulter $94 / 95+$ no LLI & 46 & 42 \\
\hline \multirow[t]{2}{*}{3} & High consulter $94 / 95$ + role disability & 52 & 51 \\
\hline & High consulter $94 / 95$ + no role disability & 43 & 38 \\
\hline \multirow[t]{2}{*}{4} & High consulter $94 / 95$ + physical limitation & 54 & 55 \\
\hline & High consulter $94 / 95$ + no physical limitation & 44 & 41 \\
\hline \multirow[t]{4}{*}{5} & High consulter $94 / 95$ + role disability + physical limitation & 55 & 56 \\
\hline & High consulter $94 / 95$ + role disability + no physical limitation & 47 & 44 \\
\hline & High consulter $94 / 95$ + physical limitation + no role disability & 49 & 47 \\
\hline & High consulter $94 / 95$ + no role disability + no physical limitation & 41 & 36 \\
\hline
\end{tabular}

\section{RESULTS}

\section{Frequency of consultation}

Table 1 gives details of the study cohort. There were significant differences $(\mathrm{p}<0.01)$ between high and non-high consulters at baseline (defined either by all contacts or by diagnostic Chapter consultations only) for all baseline variables in univariate analyses.

Table 2 shows that a high consulter in 1994/95 was more likely than a non-consulter or average consulter to be a high consulter in 1997/98, independent of LLI (odds ratio 5.61 for all contacts, 4.44 for the diagnostic Chapter subgroup). After the effect of the 1994/95 consultation frequency is taken into account, there was an added predictive effect of reported LLI.

In the stepwise model (table 2), a high consultation rate in 1994/95 was the strongest predictor. The other significant predictor was role disability. Physical limitations was also a predictor for the diagnostic subgroup only. LLI status, emotional limitations, and unfavourable personal evaluation were not selected as predictors in either of the final models.

Table 3 shows the estimated probability (expressed as a percentage) of being a high consulter in 1997/98 for a 50 year old woman residing in an area with Townsend score 0 (that is, the average for the area) for different levels of consultation in 1994/95 and various predictor variables (based on the binary logistic models in table 2). For all contacts, previous high consultation gives a $49 \%$ likelihood of being a subsequent high consulter (model 1). Little additional information is gained separately from LLI status, role disability, or physical limitation (models 2-4). However, the two SF-36 indicators together add to the consultation data; having neither a physical limitation nor a role disability reduces the likelihood of being a subsequent high consulter to $41 \%$, having both increases it to $55 \%$. The models for the diagnostic subgroup are similar.

\section{Individual diagnostic Chapters}

Predictors of subsequent consultation within the individual diagnostic Chapters are shown in tables 4 and 5 . Table 4 shows the models with previous consultation in that Chapter and reporting of LLI as the predictor variables (adjusted for age, gender, and Townsend score). Consultation at baseline was significantly associated with future consultation in the same Chapter for all but infectious and parasitic diseases. For example, consulters in 1994/95 under a musculoskeletal code had 2.6 times the odds (than someone who did not) of consulting with a musculoskeletal code in 1997/98. Reporting LLI was significantly associated with future consultations within some individual Chapters, but associations were weaker than for previous consultation.

The link between LLI and subsequent consultation for musculoskeletal, circulatory, and nervous conditions persisted when the stepwise procedure was performed (table 5). Emotional limitation was a significant predictor of future consultations for mental disorders and physical limitation was a significant predictor for consultations for respiratory system diseases, digestive system diseases, skin diseases, and musculoskeletal diseases. Unfavourable personal evaluation 
Table 4 Association with subsequent consulting in 1997/98 for individual diagnostic Chapters of LLI at baseline and consultation in 1994/95*

\begin{tabular}{|c|c|c|c|}
\hline Chapter & Number† & $\begin{array}{l}\text { Consulted 94/95‡ } \\
\text { OR }(95 \% \mathrm{Cl})\end{array}$ & $\begin{array}{l}\text { LLI at baseline } \S \\
\text { OR }(95 \% \mathrm{CI})\end{array}$ \\
\hline A: Infectious & $60(8 \%)$ & 1.31 (0.59 to 2.92$)$ & $1.30(0.74$ to 2.28$)$ \\
\hline E: Mental & $65(9 \%)$ & $4.22(2.20$ to 8.06$)$ & 1.64 (0.94 to 2.89 ) \\
\hline F: Nervous & $124(17 \%)$ & $3.79(2.46$ to 5.85$)$ & 1.56 (1.00 to 2.42$)$ \\
\hline G: Circulatory & $83(11 \%)$ & 2.53 ( 1.47 to 4.37$)$ & 1.84 (1.09 to 3.12$)$ \\
\hline $\mathrm{H}$ : Respiratory & $223(30 \%)$ & $2.58(1.85$ to 3.60$)$ & 1.27 (0.90 to 1.79 ) \\
\hline I: Digestive & $84(11 \%)$ & $3.80(2.26$ to 6.38$)$ & 1.23 (0.75 to 2.00$)$ \\
\hline J: Genitourinary & 93 (13\%) & $3.68(2.23$ to 6.06$)$ & $1.52(0.93$ to 2.46$)$ \\
\hline L: Skin & $128(17 \%)$ & 2.96 (1.91 to 4.58$)$ & 1.57 (1.04 to 2.38 ) \\
\hline M: Musculoskeletal & $239(32 \%)$ & 2.57 ( 1.84 to 3.60$)$ & 2.01 (1.42 to 2.85 ) \\
\hline $\mathrm{P}$ : Injury/poisoning & $63(9 \%)$ & 2.51 ( 1.31 to 4.82 ) & $1.41(0.80$ to 2.47$)$ \\
\hline
\end{tabular}

*Adjusted for age, gender, and Townsend deprivation score and other variable shown. Bold indicates $\mathrm{Cl}$ does not include 1.00. †Number consulting under diagnostic Chapter in 1997/98. $‡$ Consultation in same Chapter, compared with no consultation in that Chapter. §Compared with reporting no LLI.

Table 5 Selected predictors for consulting under individual diagnostic Chapters in 1997/98*

\begin{tabular}{|c|c|c|c|c|c|c|}
\hline \multirow[b]{2}{*}{ Chapter } & \multicolumn{6}{|l|}{ OR $(95 \% \mathrm{Cl})$} \\
\hline & $\begin{array}{l}\text { Consulted 94/95 } \\
\text { ( } v \text { no consult) }\end{array}$ & $\begin{array}{l}\text { LLI at baseline } \\
\text { ( } v \text { no LLI) }\end{array}$ & $\begin{array}{l}\text { Physical Limitation } \\
\text { ( } v \text { no limitation) }\end{array}$ & $\begin{array}{l}\text { Emotional } \\
\text { Limitation } \\
\text { I }(v \text { no limitation })\end{array}$ & $\begin{array}{l}\text { Role Disability } \\
\text { ( } v \text { no disability) }\end{array}$ & $\begin{array}{l}\text { Unfavourable } \\
\text { Personal Evaluation } \\
\text { (v favourable) }\end{array}$ \\
\hline A: Infectious & - & - & - & - & - & 2.78 (1.54 to 5.01$)$ \\
\hline E: Mental & 3.05 (1.50 to 6.20$)$ & - & - & 2.41 (1.27 to 4.57 ) & - & - \\
\hline F: Nervous & 3.79 (2.46 to 5.85$)$ & 1.56 (1.00 to 2.42 ) & - & - & - & - \\
\hline G: Circulatory & 2.53 (1.47 to 4.37 ) & 1.84 (1.09 to 3.12$)$ & - & - & - & - \\
\hline H: Respiratory & 2.47 (1.76 to 3.48 ) & - & 1.84 (1.27 to 2.66$)$ & - & - & - \\
\hline I: Digestive & 3.81 (2.24 to 6.46$)$ & - & 1.81 (1.06 to 3.10$)$ & - & - & - \\
\hline J: Genitourinary & 3.84 (2.32 to 6.36$)$ & - & - & - & - & - \\
\hline L: Skin & 3.16 (2.02 to 4.93$)$ & - & 2.03 (1.31 to 3.17$)$ & - & - & - \\
\hline M: Musculoskeletal & $2.40(1.70$ to 3.40$)$ & 1.54 (1.02 to 2.32 ) & 1.72 (1.13 to 2.62 ) & - & - & - \\
\hline P: Injury/poisoning & $2.66(1.37$ to 5.15$)$ & - & - & - & 2.02 (1.12 to 3.63$)$ & - \\
\hline
\end{tabular}

was the best predictor for subsequent infectious disease consultations. Role disability predicted injuries and poisoning consultations best of the self report health related variables.

\section{DISCUSSION}

Previous consultation frequency is a stronger predictor for subsequent consultation frequency than measures of self reported health status. The simple conclusion is that future health demand, as measured by consultations with the general practitioner, is most usefully estimated from routinely collected general practice data than from one off general population surveys. The implication for planning by primary care groups and public health departments is that adequate resources should be directed towards supporting and improving routine primary care data collection.

There are caveats to this. Firstly, the need for health care among those who do not consult requires a different measure. Our earlier work ${ }^{4}$ indicated that there are groups of people who report LLI and score poorly on the SF-36 but who, for a range of reasons, do not consult. However, such an issue tackles a different question, namely how unexpressed need should be measured, evaluated, and met. Secondly, our model of an individual in table 3 underlines that there are other reasons for high consultation than those considered here. As well as medical reasons, these might also include doctor characteristics (for example, in recommending review visits) and features of patients and their social circle. ${ }^{12}$

The similar results for the all contacts and the subgroup analyses highlight the predictive strength of contact data in general. However, the strong association within diagnostic Chapters between past and future consultations also emphasises that specificity of morbidity coding will improve the

\section{Key points}

- Recent primary care consultation frequency is a stronger predictor for future consultation frequency than current self reported health status.

- Consultation leading to a particular diagnosis is a strong predictor of future consultation diagnosis within the same disease group.

- Periodic surveys may usefully enhance primary care records in predicting future consultation but their main function may be to identify poor health in non-consulters.

- Good primary care morbidity recording is needed to help plan for future demands on health care.

quality of prediction. The practices within the North Staffordshire General Practice Network are increasingly being encouraged to record consultations under a diagnostic code. This still allows for uncertainty, for example, when consultations are about symptoms whose cause is unclear, but encourages standard classification of such symptoms.

While the LLI question predicted consultations in certain disease categories in the subsequent two years, it is not a major predictor of overall consultation. The physical and emotional limitation indicators of the SF-36 did show a link with the corresponding disease Chapters and the physical limitation and role disability indicators did improve prediction of frequency of overall consultation. However, the SF-36 is more complicated, takes longer to complete, and is more likely to result in missing data than the LLI question. The LLI question is related to the SF-36, particularly to the physical dimensions. ${ }^{13}$ The SF-36 physical limitation indicator was more strongly related to subsequent frequency of consultation 
within the non-LLI group (among non-consulters in 1997/98 $15 \%$ had a physical limitation at baseline, average consulters $22 \%$, high consulters $37 \%, \chi^{2}$ test for trend $p=0.001$ ) than in the LLI group $\left(71 \%, 73 \%\right.$, and $80 \%$ respectively, $\chi^{2}$ test for trend $\mathrm{p}=0.12)$. The interaction term for LLI and physical limitations did not, however, improve the final models shown in table 2.

The multistage design of the study reduced response in terms of those who had their records reviewed. However, the only difference between those consenting to record review and those not is that the consenters were slightly older (difference in means 3.7 years, $95 \%$ CI 2.3 to 5.1 ). There is no reason to believe that the baseline non-response affects our conclusions. More relevant to this cohort study was the low loss to follow up, an advantage of using consultation data as an outcome measure.

It would be beneficial to repeat this work in the UK within other practices. Although the study practice resides in an area reflecting a wide range of socioeconomic status, ethnic minorities, for example, are under-represented. Although the results of our study are likely to be generalisable to other general practices in the UK, a more difficult question is their relevance to other countries and healthcare systems. The unique reliance on general practice as the point of access to the whole healthcare system in the UK means that our data can provide a reasonably complete account of illness for which health care is sought in a general population. In countries where people can access health care from a variety of sources, general practice data may be an incomplete picture of morbidity and be less useful for health planning. However, if data are available on the full range of healthcare use, then the findings from our study are likely to be generalisable-namely that current consultation patterns are a strong predictor of future consultation-with the same practical implications for policy and planning as we have outlined for the UK situation.

The implication of this study is that good morbidity recording is needed to help plan for future demands on health care. Opportunistic use of the LLI question or periodic surveys may usefully improve practice records but their main function might be to identify poor health in non-consulters.

\section{ACKNOWLEDGEMENTS}

The authors thank Tracy Whitehurst and Rhian Hughes who extracted the consultation data, the general practice itself, everyone who took part in the survey and the anonymous referees who gave helpful comments on the original draft of the paper.

\section{Authors' affiliations}

K Jordan, P Croft, Primary Care Sciences Research Centre, Keele University, Keele, UK

B N Ong, Faculty of Health, Keele University

Funding: funding for the study was originally provided by North Staffordshire Health Authority and North Staffordshire Medical Institute, UK. Completion of the study was also supported through funding from the NHS(E) West Midlands R\&D Directorate.

Conflicts of interest: none.

\section{REFERENCES}

1 Cook DG, Morris JK, Walker $M$, et al. Consultation rates among middle aged men in general practice over three years. BMV 1990;301:647-50.

2 Carr-Hill RA, Rice N, Roland M. Socioeconomic determinants of rates of consultation in general practice based on fourth national morbidity survey of general practices. BM 1996;312:1008-12.

3 Scaife B, Gill PS, Heywood PL, et al. Socio-economic characteristics of adult frequent attenders in general practice: secondary analysis of data. Fam Pract 2000; 17:298-304

4 Jordan K, Ong BN, Croft P. Researching limiting long-term illness. Soc Sci Med 2000;50:397-405

5 Ware JE, Snow KK, Kosinski M. SF-36 Health Survey: manual and interpretation guide. Lincoln, RI: QualityMetric Incorporated, 2000.

6 Rose MS, Koshman ML, Spreng S, et al. Statistical issues encountered in the comparison of health-related quality of life in diseased patients to published general population norms: problems and solutions. J Clin Epidemiol 1999;52:405-12.

7 Townsend P, Phillimore P, Beattie A. Health and deprivation: inequality and the north. London: Croom Helm, 1988.

8 NHS Information Authority. The clinical terms version 3 (The Read Codes). Birmingham: NHS Information Authority, 2000

9 Greene WH. Econometric analysis. 4th edn. London: Prentice-Hall, 2000.

10 SPSS. SPSS for Windows, Rel. 10.0.7. Chicago: SPSS, 2000

11 StataCorp. Stata statistical software: release 6.0. College Station, TX: Stata Corporation, 1999.

12 Neal RD, Heywood PL, Morley S. 'I always seem to be there' - a qualitative study of frequent attenders. Br J Gen Pract 2000:50:716-23.

13 Cohen G, Forbes J, Garraway M. Interpreting self reported limiting long term illness. BM 1995;311:722-4. 